I think that you are going to be a fine cartographer, how else could we have found you in each other?

Last night, he taught me, your almost-father, if I tie a string to Orion's right shoulder

and follow to its end in the steady wind that rises

when the stars put on their names and sweep forward to be counted,

I will see an eddy of snow, a faint balloon.

I think it is the galaxy

where certain children go

to live out their first lives;

it's full of smaller pinwheels and a sweet wind

to wheel them so the ones who have no lungs

can use instead the breath of the world-

the big world, the forgiving one.

\title{
Quintet for Flute and Strings
}

For years I've been sad

over somebody you didn't know,

somebody who walked the earth

while you did, but so what. Today

you gave me a little piece of music

you have written for the flute-

the flute I learned to play

so long before the angel

was given his assignment

to come down and uproot

the garden of my heart -

and when I looked at it I saw 
how you'd plowed the staves' furrows and unearthed the gleaming notes from the sky where it is blackest (as, after someone's taken there they close the sky behind him and keep it locked awhile until they know he sees by the faint watts of his body and won't go grabbing the stars from their sockets); when we played it I heard a voice as through a door ajar that kept on not listening to anything it meant in me, kept speaking in the soft voice I think God will use to ask all the faces to lay down their tears and wash the charred world - and then everything sighed: the chair first, offering its sturdy wood, the four bowing arms it had rested on so long; then the body, so amazed to be hearing that sound that it rose from the chair where its life had been passing and asked itself to dance, please, asked what finally woke you, what woke you up so pretty, what star gave you the money for such a silver gown? 